\title{
Polycystic Ovarian Syndrome Burden in Central India: A Cross-Sectional Study
}

Kshitij RB Singh, Sree Lekshmi KK, Diptimayee Manasingh ${ }^{1}$, Srusti Badajena ${ }^{1}$, Parikipandla Sridevi*

Department of Biotechnology, Faculty of Science, Indira Gandhi National Tribal University, Amarkantak, Madhya Pradesh (484886), India.

*Corresponding author: Parikipandla Sridevi, Department of Biotechnology, Faculty of Science, Indira Gandhi National Tribal University, Amarkantak, Madhya Pradesh (484886), India.

Received date: March 27 2020; Accepted date: May 17, 2020; published date: June 05, 2020

Citation: Kshitij RB Singh, Sree Lekshmi KK, Diptimayee Manasingh, Srusti Badajena, Parikipandla Sridevi. Polycystic Ovarian Syndrome Burden In Central India: A Cross-Sectional Study. J Clinical Research and Reports, 4(3); DOI:10.31579/2690-1919/095

Copyright: (C) 2020 Parikipandla Sridevi. This is an open access article distributed under the Creative Commons Attribution License, which permits unrestricted use, distribution, and reproduction in any medium, provided the original work is properly cited.

\section{Abstract}

Background: Polycystic Ovarian Syndrome (PCOS) is a common endocrine syndrome with the disproportionate activity of androgen. This study is intended to determine attitudes with respect to the present names for the syndrome and acuities held by women regarding the main clinical features of PCOS. The study compares the status of PCOS patients and reproductive-aged tribal women prone to PCOS in the population of Central India at Amarkantak.

Methods: A cross-sectional study was performed in which a sample size of 500 females by random sampling was considered for the study and a well-validated questionnaire following the Rotterdam criteria for the diagnosis of PCOS was administered. Data collected relating to PCOS risk factors and the status of disease burden in society were analyzed using SPSS v 25.

Results: The prevalence of the PCOS was around 6.6\% owing to wretched lifestyle practices. Midst them, the risk factors were depression/anxiety in $32.2 \%$, obesity in $28.4 \%$, and diabetes in $7.6 \%$ and infertility in $1.8 \% .86 .6 \%$ of people were unaware of the disorder and $41.8 \%$ of them were prone to PCOS.

Conclusion: Early detection and tracking of risk factors can help in the management of PCOS symptoms. A population-based program of screening and awareness including treatment modalities may be beneficial for the management of the disease.

Keywords: Polycystic ovarian syndrome; PCOS; Infertility; Hirsutism; Hyperandrogenism.

\section{Introduction}

Polycystic Ovarian Disease (PCOD) stands for triad of 'Amenorrhea', 'Obesity' and 'Hirsutism', relating to reproductive disorders [1]. Henceforth, it is also known as the hyper androgenic disorder, affecting nearly $6-10 \%$ of reproductive-aged women and is the most common endocrine metabolic disorder as it can be associated with metabolic concerns like obesity, insulin resistance, hyper-insulinemia and type 2 diabetes mellitus (TD2M) [2]. The disorder can be depicted by hyperandrogenemia (biochemical primarily) and polycystic ovaries (morphological) and PCOD can be associated to risk factors like cardiovascular problems, neuro-psychological effects, endometrial and breast cancers secondarily [3].

Over the last 15 years, the outline of disease status in India in general and mainly in rural India has endured a significant shift. Government of India report in 2001-2003 presented an early suspicion of this change on the causes of death in the country. Deaths in rural India due to communicable diseases ( $41 \%$ ), according to the report, correspond to those due to non-communicable diseases (NCDs) (40\%). It is evident from the data of WHO that, the total NCD mortality was approximately $40 \%$ whereas the premature NCD mortality was $48 \%$ [4]. PCOD is now considered as a lifestyle disorder and till date there has been no cause identified for this disorder. Thus, genetic and environmental aspect play a major role in etiology.

Clinical aspects in case of PCOS show a very broad-spectrum criteria for diagnosis. Ovulatory dysfunction cannot be confined by the presence of oligomenorrhea only, as diagnosis shall be appropriate also when progesterone levels are $<3-4 \mathrm{ng} / \mathrm{mL}$ in 20-24 days of menstrual cycle. In contrast hyperprogesteronemia can also result in anovulation in at least 2 cycles which can also make the patient anovulatory. Presence of acanthosis nigricans with symptoms of hyperandrogenism also shows to be criteria for diagnosis for PCOS [5]. According to the 2003 Rotterdam PCOS census, women with anovulation can be evaluated with early failure of ovarian considered for low E2 (estradiol test) and high FSH (Follicle stimulating hormone) concentrations and also serum FSH and E2 levels to exclude hypogonadotropic hypogonadism characterized according to the World Health Organization (WHO) classification [6]. Women with PCOS were observed with elevated levels of circulating LH (Lieutinizing hormone) as well as it relates to FSH levels [7]. PCOS affected women with frequent risk of developing type 2 diabetes at an occurrence of 3-7 times $[8,9]$. There is also a clear evidence of women with PCOS in high risk for developing cardiovascular diseases [10]. Abnormal vascular function (11) and the high chances of incidence to dyslipidemia (12) also risk women affected with PCOS. PCOS patients when assessed show an inverse correlation to metabolic risk factors that are; insulin resistance, BMI, triglycerides, waist-to-hip ratio and total testosterone to Vitamin D and positively correlates to insulin sensitivity (13-15).

\section{Reasons of threat-}

\section{Cardiovascular problems}

According to the global action plan for the precaution and control of NCDs 2013-2020, that includes 25\% relative reduction in premature mortality from cardiovascular diseases, cancer, diabetes or chronic respiratory diseases by 2025 (16). In January 1997, a study held at NewZealand reported that women who had heart diseases also with 8/>\% ovarian cysts, was $42 \%$ when compared to women without heart diseases were $22 \%$ (17). Henceforth, the conditions in which they live and work 
should be recognized and also the lifestyle that influences their health and quality of life should be monitored.

\section{Obesity}

It is observed that, $50 \%$ of PCOS women are affected by obesity. As per the WHO data till 2016, $39 \%$ of women aged 18 and above are overweight (18). Typically, present in patients who get affected with upper body obesity are found to be linked with menstrual instabilities (19). Earlier the condition of obesity was found to be a cause of PCOS, but now it has been observed to be a modifier of the disorder (20).

\section{Infertility}

PCOS has another ambiguous difficulty of infertility as it affects the ovulation and fertility with $75 \%<$ anovulation infertility in women (21). American Society for Reproductive medicine reports that after six months of pregnancy attempt failure once the couple had sexual intercourse more than two times deprived of any contraceptive measures, then infertility in women with PCOS should be examined (22).

This survey depicts the assessment and analysis of PCOS burden in the middle aged-women in Central India. Furthermore, the risk factors related to the disease was evaluated based on the comparative study and the burden of the disease was summarized among the population.

\section{Methods-}

The cross-sectional study was performed in the tribal population of Amarkantak region, district Anuppur, Madhya Pradesh, India. Survey material was developed by strictly following the 2003 Rotterdam consensus in this consensus group of scientists and medical practitioner decided that PCOS is a syndrome of ovarian dysfunction, and also shows some key features like polycystic ovary (PCO) morphology and hyperandrogenism. For PCOS single clinical diagnosis criteria is not sufficient such as hyperandrogenism or PCO. Menstrual irregularities, signs of androgen excess, and obesity are some of its clinical manifestations. Insulin resistance and elevated serum LH levels along with risk of having type 2 diabetes and cardiovascular problems are also common features in PCOS (23). After the development of questionnaire, it was tested by presurvey analysis before going for the final administration. A total of 22 questions were asked to 500 female subjects from age group between 15-45 years. This is a survey-based study for the assessment, analysis and awareness program of PCOS in the tribal population. The participants who were included in the survey are students of higher secondary school, colleges/university and women working to earn their living. The reason to select this age group for study is that adolescent girls, and middle-aged women have developed reproductive abilities so chance of getting diagnosed or having PCOS are more in this age group. Children's and women's after menopause, are excluded from the study as they are not having menstrual disturbances or any symptoms of PCOS. The questionnaire prepared was utilized to take interview for data collection by random sampling method and for the study, the local tribal population of Pondki and Lalpur village of Amarkantak region was selected. The study was steered from February to June of 2019. In the first month the questionnaire was framed and validated. Subsequent four months were for the data collection and data analysis. Before going for the survey few hypotheses were framed as follows

1) PCOS have become a very major health problem among the young girls as more than $50 \%$ of reproductive-aged girls are prone to PCOS.

2) Most of the women suffering from PCOS are associated with infertility, diabetes etc.
3) Lack of knowledge and less awareness about PCOS is prevalent in this area.

After hypothesis was framed data was collected by conducting personal interviews and spreading awareness among the population was also carried out simultaneously to the respondents regarding PCOS risk factors after interview. For this study the ethical approval was taken from the institutional ethics committee as ethics are the prime concern, as the data collected regarding the personal aspect of an individual is very confidential and in this project the data was utilized only for analysis and assessment of PCOS, the surveyor obtained consent from the subjects prior to the data collection by assuring confidentiality, to the subject to get their cooperation and explained the purpose of the study and the results were kept confidential. Data regarding socio-demographic profile (sex, date of birth, weight, and height), lifestyle status, nutritional habits, menstrual cycle status (oligomenorrhea), chronic anovulation, diabetes, anxiety/depression, obesity, hirsutism, hyperandrogenism and awareness of PCOS among the population was collected.

While collecting the data medical history was recorded, with clinical, anthropometric, and biochemical (LH, FSH, triglycerides $\geq 150 \mathrm{mg} / \mathrm{dL}$, HDL-C $<50 \mathrm{mg} / \mathrm{dL}$, etc.) parameters and subjects already diagnosed with PCOS on these parameters were assessed to get prevalence of this syndrome in tribal society. As there is no validated tool available for making clinical diagnosis of PCOS in the study, Rotterdam criteria of PCOS was considered and by seeing the clinical report of already suffering patients from PCOS and the symptoms of PCOS in population, we have come to conclusion for prevalence of PCOS and Prone to PCOS among the population. After the analysis the participant likely to have PCOS were asked to go for further clinical and ovarian ultrasound examination under the supervision of gynecologist for detailed diagnosis of the disease and the girls with BMI more than $23 \mathrm{~kg} / \mathrm{m}^{2}$ were asked for dietary interventions along with counselling for PCOS The data of weight and height was analyzed to get BMI (Body Mass Index) of the population using the formula of BMI preferred by CDC (Centers for Disease Control \& Prevention) (24) as given below:

Formula: weight $(\mathrm{kg}) /[\text { height }(\mathrm{m})]^{2}$

Calculation: [weight $(\mathrm{kg}) /$ height $(\mathrm{cm}) /$ height $(\mathrm{cm})$ ] x 10,000

After the BMI calculation using the formula given by $\mathrm{CDC}$, it was analysed according to $\mathrm{CDC}$ criteria for Adult BMI range the BMI Less than $18.5 \mathrm{~kg} / \mathrm{m}^{2}$ was considered as underweight; $18.5 \mathrm{~kg} / \mathrm{m}^{2}$ to 24.9 $\mathrm{kg} / \mathrm{m}^{2}$, it falls within the normal or Healthy Weight range; $25.0 \mathrm{~kg} / \mathrm{m}^{2}$ to $29.9 \mathrm{~kg} / \mathrm{m}^{2}$, falls within the overweight range; $30.0 \mathrm{~kg} / \mathrm{m}^{2}$ or higher is within the obese range (25). The data was entered in MS Excel spreadsheet as well as in SPSS spreadsheet and analyzed based on comparison of age with hirsutism, menstrual cycle, and disease status; comparison of risk factors with disease status; and finally validation of the framed hypothesis using mean and proportion, Chi square test, ANOVA (One way ANOVA), and Student t-test (Independent sample ttest) analysis was performed with the help of statistical software SPSS v. 25 and $\mathrm{p}$-value of $<0.05$ was examined as significant.

\section{Results}

The study shows a socio-demographic profile of 500 women, from which the mean age and mean BMI of the participants were $23.6( \pm 1.4)$ years and $22.5( \pm 4.6) \mathrm{kg} / \mathrm{m}^{2}$ respectively. A total of 10 patients claim to have PCOS with an average BMI of $30.85 \mathrm{~kg} / \mathrm{m}^{2}( \pm 2.8)$. With respect to further investigation $28.4 \%( \pm 0.4 \%)$ were reported to be obese. Depression and anxiety were present in $32.2 \%( \pm 0.4 \%)$, diabetes existed in $7.6 \%( \pm 0.2 \%)$ and $1.8 \%( \pm 0.1 \%)$ was reported with infertility (Table 1$)$. 
Table-1: Socio-demographic and distribution of PCOS risk factors profile

\begin{tabular}{|c|c|c|}
\hline Variables & \multicolumn{2}{|c|}{ Mean } \\
\hline Age & \multicolumn{2}{|c|}{23.6 years } \\
\hline BMI & \multicolumn{2}{|c|}{$22.5 \mathrm{~kg} / \mathrm{m}^{2}$} \\
\hline PCOS Patients BMI & \multicolumn{2}{|c|}{$30.85 \mathrm{~kg} / \mathrm{m}^{2}$} \\
\hline Risk Factor & Frequency (\%) & P-value \\
\hline Obesity & $142(28.4 \%)$ & $.000 *$ \\
\hline Depression/anxiety & $161(32.2 \%)$ & $.000 *$ \\
\hline Diabetes & $38(7.6 \%)$ & $.000 *$ \\
\hline Infertility & $9(1.8 \%)$ & $.000 *$ \\
\hline *Statistically signifi & fference & \\
\hline
\end{tabular}

Table. 1- Socio-demographic and distribution of PCOS risk factors profile

From the study, it was estimated that $14.8 \%( \pm 0.5 \%)$ were adolescent girls in the age group of $15-20$ years whereas $24.4 \%( \pm 0.5 \%)$ of young girls were in the group of 21-25 years who were prone to PCOS. It was also evident from the study that the frequencies of subjects having PCOS were $1.8 \%( \pm 0.9 \%)$ in the group of $15-20$ years of age and $3.2 \%$ $( \pm 0.9 \%)$ in the age group of 21-25 years which was comparatively higher to other sets of age (Table 2).

\begin{tabular}{|c|c|c|c|}
\hline \multicolumn{4}{|c|}{$\begin{array}{l}\text { Table-2: Comparative analysis of Age group with } \\
\text { PCOS status }\end{array}$} \\
\hline Age & & Frequency $(\%)$ & P-value \\
\hline \multirow{2}{*}{$15-20$} & Has PCOS & $9(1.8 \%)$ & \multirow{10}{*}{$.000^{*}$} \\
\hline & Prone to PCOS & $74(14.8 \%)$ & \\
\hline \multirow{2}{*}{$21-25$} & Has PCOS & $16(3.2 \%)$ & \\
\hline & Prone to PCOS & $122(24.4 \%)$ & \\
\hline \multirow{2}{*}{$26-30$} & Has PCOS & $3(0.6 \%)$ & \\
\hline & Prone to PCOS & $13(2.6 \%)$ & \\
\hline \multirow{2}{*}{$31-35$} & Has PCOS & $3(0.6 \%)$ & \\
\hline & Prone to PCOS &.---- & \\
\hline \multirow{2}{*}{$36-45$} & Has PCOS & - -.-- & \\
\hline & Prone to PCOS &.---- & \\
\hline *Statistic & ignificant differ & & \\
\hline
\end{tabular}

Table. 2- Comparative analysis of Age group with PCOS status From our analysis $12.6 \%( \pm 0.8 \%)$ of girls in the age group of $15-20$ years and $23.8 \%( \pm 0.8 \%)$ of girls in the age group of $21-25$ years suffer from menstrual disturbances. It is also evident that a very less proportion do suffer from menstrual problems in the age group of 26-30 years, that is just $5.8 \%( \pm 0.8 \% \%)$ and much less in case of 31-35 and 3645 years of age group, $1.6 \%( \pm 0.8 \%)$ and $1.2 \%( \pm 0.8 \%)$ respectively (Table 3).

\begin{tabular}{|c|c|c|c|c|}
\hline \multicolumn{5}{|c|}{ Table-3: Comparative analysis of Age group with Menstrual cycle } \\
\hline Age & Menstrual cycle & Frequency & Percentage (\%) & P-value \\
\hline \multirow{2}{*}{$15-20$} & Irregular & 63 & 12.6 & \multirow{10}{*}{.037} \\
\hline & Regular & 48 & 9.6 & \\
\hline \multirow{2}{*}{$21-25$} & Irregular & 119 & 23.8 & \\
\hline & Regular & 138 & 27.6 & \\
\hline \multirow{2}{*}{$26-30$} & Irregular & 29 & 5.8 & \\
\hline & Regular & 54 & 10.8 & \\
\hline \multirow{2}{*}{$31-35$} & Irregular & 8 & 1.6 & \\
\hline & Regular & 22 & 4.4 & \\
\hline \multirow{2}{*}{$36-45$} & Irregular & 6 & 1.2 & \\
\hline & Regular & 13 & 2.6 & \\
\hline & Total & 500 & 100 & \\
\hline
\end{tabular}

Table. 3- Comparative analysis of Age group with Menstrual cycle

It was stated that girls had the occurrence of hirsutism in $10.32 \%( \pm 0.8 \%)$ and $27.74 \%( \pm 0.8 \%)$ in the age of $15-20$ years and $21-25$ years respectively. Comparatively a lesser section has hirsutism with $6.45 \%( \pm 1.08 \%)$ and $1.93 \%( \pm 1.08 \%)$ in the set of $26-30$ and $31-35$ years of age respectively. The lowest fraction was for the age group of 36-45 years which had only $0.64 \%$ for the occurrence of hirsutism (Table 4 ). 


\begin{tabular}{|c|l|c|c|}
\hline \multicolumn{4}{|c|}{ Table-4: Comparative analysis of Age group with Hirsutism } \\
\hline \multirow{2}{*}{ Age } & \multicolumn{1}{|c|}{ Hirsutism } & Frequency & Percentage \\
\hline \multirow{2}{*}{$15-20$} & YES & 52 & 10.4 \\
\cline { 2 - 4 } & NO & 58 & 11.6 \\
\hline \multirow{2}{*}{$21-25$} & YES & 138 & 27.6 \\
\cline { 2 - 4 } & NO & 119 & 23.8 \\
\hline \multirow{2}{*}{$26-30$} & YES & 32 & 6.4 \\
\cline { 2 - 4 } & NO & 54 & 10.8 \\
\hline \multirow{3}{*}{$31-35$} & YES & 9 & 1.8 \\
\cline { 2 - 4 } & NO & 19 & 3.8 \\
\hline \multirow{2}{*}{$36-45$} & YES & 3 & 0.6 \\
\cline { 2 - 4 } & NO & 16 & 3.2 \\
\hline \multicolumn{2}{|c|}{ Total } & $\mathbf{5 0 0}$ & $\mathbf{1 0 0}$ \\
\hline
\end{tabular}

Table. 4- Comparative analysis of Age group with Hirsutism

Finally, our study results show that burden of PCOS status in this particular region is projected quite seriously as $6.6 \%( \pm 0.6 \%)$ of the total population, and just $13.4 \%( \pm 0.3 \%)$ of the total population has the proper awareness about the PCOS when the majority of $86.6 \%( \pm 0.3 \%)$, yet unaware about the pros and cons of this disorder, $41.8 \%( \pm 0.6 \%)$ of the population is shown to be prone to PCOS (Table 5).

\begin{tabular}{|c|l|c|c|c|}
\hline \multicolumn{5}{|c|}{ Table-5: PCOS burden and its awareness status among the } \\
population \\
\hline Variables & & Frequency & Percentage & P-value \\
\hline \multirow{3}{*}{ PCOS Burden } & YES & 33 & 6.6 & \multirow{2}{*}{$.000 *$} \\
\cline { 2 - 5 } & PRONE & 209 & 41.8 & \\
\cline { 2 - 5 } & NO & 258 & 51.6 & \multirow{2}{*}{$.000 *$} \\
\hline \multirow{2}{*}{ Awareness of PCOS } & YES & 67 & 13.4 & \\
\cline { 2 - 5 } & NO & 433 & 86.6 & \\
\hline *Statistically significant difference & & & \\
\hline
\end{tabular}

Table. 5- PCOS burden and its awareness status among the population In the comparative analysis of lifestyle factor with PCOS it can be stated that the subjects with pathetic lifestyle practices are prevalent to PCOS (Figure 1).

\section{Comparison of Lifestyle with PCOS burden in society.}

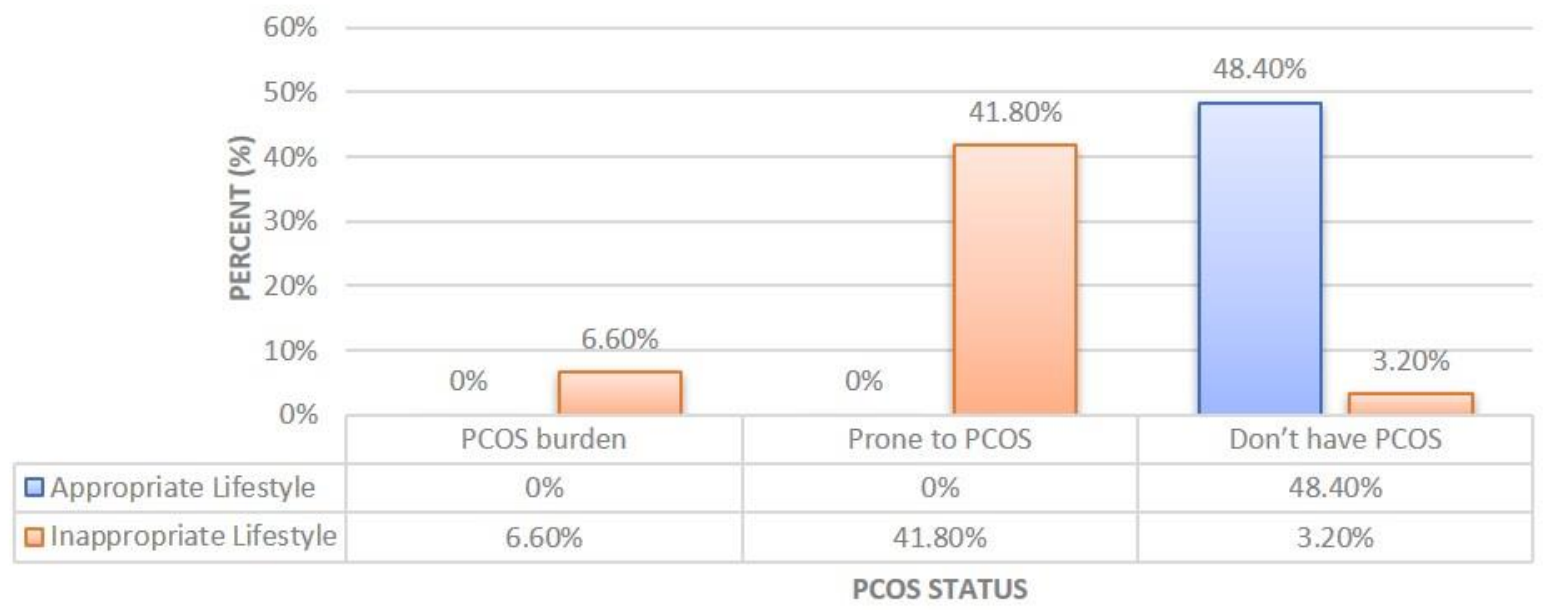

Fig. 1- Comparison of Lifestyle with PCOS burden in society.

\section{Discussion}

India has witnessed about $30 \%$ rise in PCOS cases in the last couple of years. Lack of knowledge and lifestyle changes are considered to be the major factor leading to this phenomenon (26). Hence, PCOS have startled more than half number of the adolescent and young aged girls who are becoming susceptible. Girls of adolescent age group (15-20 years) are likely to get affected with PCOS (27). The prevalence of PCOS was found generally in young and reproductive aged women was assessed (28).

From the current study the risk factors are found to be more prevalent in reproductive aged women comparatively in a higher proportion, especially in the case of overweight and obesity, have a higher negative impact on the quality of their life (29). This concern was indeed raised to be more fatal than other problems like the menstrual instabilities (30). In the present study, $28.4 \%$ girls of from the total count reported to be obese and $10.4 \%$ and $27.6 \%$ in the age of $15-20$ years and $21-25$ years respectively were hirsute which are linked to raise levels of testosterone and presence of PCO on ultrasound (31). In case of overweight earlier studies prove that minimal loss of $5 \%$ of weight has shown to stabilize the menstrual disturbances and also accordingly alleviates the metal wellbeing. Hence, medical conditions of patients of PCOS can be enhanced by controlling the weight of individuals (32).

In the current study the problem of high incidence of hirsutism in most of the reproductive aged-women have shown to concern with greater emotional issues like mood swings, low esteem, worried and depressed feeling (33). Even though menstrual concerns $(34,35)$ and hirsutism (36) were risk factors for PCOS, but infertility too contributed to be a more cautious feature to the weakened quality of life (37).

The primary stage is proper awareness and diagnosis to improve the life of patients. Accurate alertness regarding the PCOS is much less as is only prevalent in $6.6 \%$ of the total population. Morbid lifestyle practices can be controlled to an extent by screening and inducing early 
interventions and endorsing a healthy lifestyle approach to halt the rise of PCOS as an emerging disorder in adolescent and young girls (38).

\section{Conclusion}

PCOS is a common hyper androgenic disorder that are found in a large number of the Indian population with exact etiology unfamiliar but pathophysiology rooted in insulin resistance, hyperandrogenism, and chronic anovulation. From this study it can be concluded that young woman of the population is having higher prevalence of PCOS. Though the major part of population is not suffering from PCOS, but higher percent is prone to this disease just because they have bad lifestyle, the main reason of bad lifestyle is their socio-economic condition as demonstrated in other study conducted to access the lifestyle parameters in this same locality by Singh et al. in 2019 (39). Current study has spread awareness among the female population about PCOS and their risk factors. We have also tried to guide the women having the risk of developing PCOS for proper diagnosis and treatment under consultation of a gynecologist. To treat PCOS, consume healthy diet, stay physically active, and it's accompanied by added medications to treat the symptoms.

Periodic screening of the candidates with positive family history of PCOS and precise initial diagnosis at early age will help the girls to live healthy life and prevent them from further health hazard.

Hence emphasis should be given on spreading awareness among the girls for lifestyle modification intended for weight loss if BMI is more than 23 , dietary interventions along with counselling of village women's for visiting government hospitals for regular checkups if they feel these symptoms of the disease. Further there are many biological materials (peptide nucleic acids (PNA), xeno-nucleic acids (XNA), threose nucleic acid, locked nucleic acid (LNA), morpholino, etc.) which can be used for making diagnostic devices for point of care diagnosis and treatment of this type of disorders $(40,41)$.

\section{Limitations of the study-}

Observatory study to identify menstrual intervals were not performed. The patients were not screened using clinical tools on biochemical parameters for PCOS such as LH, FSH, triglycerides, HDL-C, etc. This study is based on only questionnaire which is well validated and is strictly based on parameters to assess PCOS burden in society. Study has an issue relating to socio-cultural aspect as this problem is related with steroidal disturbance, infertility in women's, menstrual disturbances, etc. and these things in tribal societies are considered as taboo in the area, so collecting data was a very difficult task for the investigator along with this problem, language was also a barrier but both the problems were overcome by convincing the tribal women's of this region by talking to them in the language they are comfortable in, about this issue of PCOS by giving them knowledge about the world and Indian scenario of this syndrome, its unknown etiology, and it's pathophysiology. They were convinced to adopt a healthy lifestyle by consuming nutritious food and becoming physically active to overcome the symptoms which can later result into this syndrome.

\section{Author Statements}

- Acknowledgements- The authors would like to extend their gratitude of thanks to Dr. S. Balaswamy of Department of Statistics, Indira Gandhi National Tribal University, for helping in statistical analysis. Special thanks to all the faculty members of department of biotechnology, Indira Gandhi National Tribal University, Amarkantak, Madhya Pradesh, India.

- Author Contributions- Dr. Parikipandla Sridevi has designed the study and helped in analysis of data and writing the manuscript. Kshitij RB Singh has contributed to collection of data, data interpretation, literature search, and writing. Sree Lekshmi K. K. contributed to Literature search and writing. Diptimayee Manasingh and Srusti Badajena contributed to data collection.

- Competing interests- The authors declare that they have no conflict of interest.

- $\quad$ Funding- None.

- Ethical approval- Ethical clearance was obtained from Institutional Ethics Committee.

- Informed consent- Informed consent was obtained from all individual participants included in the study.

\section{References}

1. SteinIF, Leventhal MN. Amenorrhoea associated with bilateral Polycystic Ovaries. American Journal of Obstetrics and Gynaecology 1935; 29:181.

2. Norman RJ, Dewailly D, Legro RS, Hickey TE. Polycystic ovary syndrome. Lancet. 2007; 370:685-697.

3. Carmina E, Oberfield SE, Lobo RA. The diagnosis of polycystic ovary syndrome in adolescents. Am J Obstet Gynecol. 2010; 203:201. e1-201.e5.

4. Noncommunicable diseases (NCD) Global Health Observatory (GHO) data. (n.d.). WHO. Retrieved June 15, 2019,

5. S. P. Higgins, M. Freemark, and N. S. Prose, "Acanthosis nigricans: a practical approach to evaluation and management," Dermatology Online Journal,vol.14, no.9, article 2, 2008.

6. Rowe PJ, Comhaire FH, Hargreave TB. Female partner. In: World Health Organization manual for the standardized investigation and diagnosis of the infertile couple. Cambridge: Cambridge University Press, 2000:40-67.

7. Fauser BC, Pache TD, Lamberts SW, Hop WC, de Jong FH, Dahl KD. Serum bioactive and immunoreactive LH and FSH levels in women with cycle abnormalities, with or without PCOD. J Clin Endocrinol Metab 1991;73:811-7.

8. Legro RS, Kunselman AR, Dodson WC, Dunaif A. Prevalence and predictors of risk for type 2 diabetes mellitus and impaired glucose tolerance in polycystic ovary syndrome: a prospective, controlled study in 254 affected women. J Clin Endocrinol Metab 1999;84:165-9.

9. Ehrmann DA, Barnes RB, Rosenfield RL, Cavaghan MK, Imperial J. Prevalence of impaired glucose tolerance and diabetes in women with polycystic ovary syndrome. Diabetes Care 1999;22:141-6.

10. Dahlgren E, Janson PO, Johansson S, Lapidus L, Oden A. Polycystic ovary syndrome and risk for myocardial infarctionevaluated from a risk factor model based on a prospective study of women. Acta Obstet Gynecol Scand 1992; 71:599-604.

11. Christian RC, Dumesic DA, Behrenbeck T, Oberg AL, Sheedy PF II, Fitzpatrick LA. Prevalence and predictors of coronary artery calcifica- tion in women with polycystic ovary syndrome. J Clin Endocrinol Metab 2003;88:2562-8.

12. Talbott E, Clerici A, Berga SL. Adverse lipid and coronary heart risk profiles in young women with polycystic ovary syndrome: results of a case-control study. J Clin Epidemiol 1998; 51:415-22.

13. Li HW, Brereton RE, Anderson RA, Wallace AM, Ho CK (2011) Vitamin D deficiency is common and associated with metabolic risk factors in patients with polycystic ovary syndrome. Metabolism 60: 1475-1481.

14. Wehr E, Pilz S, Schweighofer N, Giuliani A, Kopera D, et al. (2009) Association of hypovitaminosis D with metabolic 
disturbances in polycystic ovary syndrome. Eur J Endocrinol 161: 575-582.

15. Yildizhan R, Kurdoglu M, Adali E, Kolusari A, Yildizhan B, et al. (2009) Serum 25-hydroxyvitamin D concentrations in obese and non-obese women with polycystic ovary syndrome. Arch Gynecol Obstet 280: 559-563

16. WHO (2013). Global action plan for the prevention and control of NCDs 2013-2020.

17. Paradisi Getal.Polycystic ovarian syndrome is associated with endothelial dysfunction. Circulation. 2001; 103:1410-1415.

18. Overweight and obesity- Global Health Observatory (GHO) data. (n.d.). WHO. Retrieved June 15, 2019.

19. GoldzieherJW, Young RL.Selected aspects of polycystic ovarian disease. Endocrinology Metabolism Clinics of North America. 1993Mar;21(1):141-171.

20. Kiddy.DS et al. Improvement in endocrine and ovarian function during dietary treatment of obese women with PCOS. Clinical Endocrinology. (Oxford)1992; 36:105-111.

21. HomburgR.The management of infertility associated with Polycystic ovarian syndrome. Reproductive Biology and Endocrinology.2003;1:109

22. Practice Committee of American Society for Reproductive Medicine. Definitions of infertility and recurrent pregnancy loss: a committee opinion. Fertil Steril. 2013;99(1):63.

23. Fauser BCJM. Revised 2003 consensus on diagnostic criteria and long-term health risks related to polycystic ovary syndrome. Fertil Steril 2004; 81:19-25.

24. Calculating BMI Using the Metric System. CDC n.d. (accessed June 15, 2019).

25. "BMI Classification". Global Database on Body Mass Index. World Health Organization. 2006. Archived from the original on April 18, 2009. Retrieved July 27, 2012.

26. Sunanda B, Nayak S. A study to assess the knowledge regarding PCOS (polycystic ovarian syndrome) among nursing students at NUINS. NUJHS. 2016;6(3).

27. Moghul S. 1 in 5, women affected by PCOS in India! but fret not, we have the solution. Health Me Up, September 7, 2015.

28. Sanchez N. A life course perspective on polycystic ovary syndrome. Int J Womens Health. 2014; 6:115- 22.
29. Nair MK, Nirmala C, Padma K, Sarma PS, Renjit M. Prevalence of Polycystic Ovary Syndrome (PCOS) Among Plus Two Girls with Menstrual Dysfunction. Trivandrum: INCLEN/ IndiaCLEN/USAID Infectious Disease Initiative; 2004.

30. McCook JG, Reame NE, Thatcher SS. Health-related quality of life issues in women with polycystic ovary syndrome. J Obstet Gynecol Neonatal Nurs 2005; 34:12-20.

31. Sanchez N. A life course perspective on polycystic ovary syndrome. Int J Womens Health. 2014; 6:115- 22.

32. Pasquali R, Gambineri A, Pagotto U. The impact of obesity on reproduction in women with polycystic ovary syndrome. BJOG 2006; 113:1148-59.

33. Norman RJ, Davies MJ, Lord J, Moran LJ. The role of lifestyle modification in polycystic ovary syndrome. Trends Endocrinol Metab 2002; 13:251-7.

34. McCook JG, Reame NE, Thatcher SS. Health-related quality of life issues in women with polycystic ovary syndrome. J Obstet Gynecol Neonatal Nurs 2005; 34:12-20.

35. Eggers S, Kirchengast S. The polycystic ovary syndrome-a med- ical condition but also an important psychosocial problem. Coll Antropol 2001; 25: 673-685.

36. Kitzinger C, Willmott J. 'The thief of womanhood': women's ex- perience of polycystic ovarian syndrome. Soc Sci Med 2002; 54: 349-361.

37. Jones GL, Hall JM, Balen AH, Ledger WL. Health- related quality of life measurement in women with polycystic ovary syndrome: a systematic review. Hum Reprod Update 2008; 14(1): 15-25.

38. Joshi B, Mukherjee S, Patil A, Purandare A, Chauhan S, Vaidya R. A cross-sectional study of polycystic ovarian syndrome among adolescent and young girls in Mumbai, India. Indian $\mathbf{J}$ Endocrinol Metab. 2014;18(3):317-24.

39. Singh, K. R. B., Fernandes, M., Sarkar, T., \& Sridevi, P. (2019). Assessment and Analysis of Lifestyle Disease Burden in Tribes of Central India. J Infect Non Infect Dis, 4, 027.

40. Singh, R. P., Oh, B.-K., \& Choi, J.-W. (2010). Application of peptide nucleic acid towards de-velopment of nanobiosensor arrays. Bioelectrochemistry, 79(2), 153-161.

41. Singh, K. R. B., Sridevi, P., Singh, R.P. (2019). Potential Applications of Peptide Nucleic Acid (PNA) in biomedical domain (Preprint).

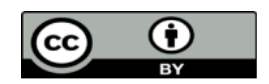

This work is licensed under Creative Commons Attribution 4.0 License
To Submit Your Article Click Here: Submit Manuscript

DOI: $10.31579 / 2690-1919 / 095$

$$
\begin{aligned}
& \text { Ready to submit your research? Choose Auctores and benefit from: } \\
& \text { fast, convenient online submission } \\
& \text { rigorous peer review by experienced research in your field } \\
& \text { rapid publication on acceptance } \\
& \text { authors retain copyrights } \\
& \text { unique DOI for all articles } \\
& \text { immediate, unrestricted online access }
\end{aligned}
$$

At Auctores, research is always in progress.

Learn more www.auctoresonline.org/journals/journal-of-clinical-researchand-reports 